\title{
Hallway Smoke Alarms: Often Specified, How Effective?
}

\author{
IAN THOMAS, and DOROTHY BRUCK \\ Centre for Environmental Safety and Risk Engineering \\ Victoria University \\ Melbourne, Australia
}

\begin{abstract}
Smoke alarms in hallways of dwellings are specified in many jurisdictions, sometimes in conjunction with others in other rooms, usually bedrooms. How effective are they compared with the same alarms in rooms but interconnected so that when one is activated they all sound? Smoke alarms have two major functions reliable and rapid detection of smoke and reliable and effective warning of building occupants. Both functions were investigated in this project, along with an analysis of 128 accidental residential building fire fatalities which showed that many of them had characteristics likely to affect their ability to respond to low level alarm sounds. The project was conducted to help determine the most appropriate location(s) of smoke alarms in dwellings in Australia. The Australian Standard for emergency notification and many other standards specify a sound level of at least $75 \mathrm{dBA}$ at the pillow. When an $85 \mathrm{dBA} 3100 \mathrm{~Hz}$ smoke alarm sound was emitted in a hallway the measured sound level in the rooms with doors closed varied from 37.4$55.9 \mathrm{dBA}$. When the doors were open the levels varied from 40.0-74.8 dBA. Thus the maximum sound level in rooms due to hallway alarms was always below the $75 \mathrm{dBA}$ recommended level and well below with the room doors closed. The time taken for a particular type of smoke alarm to activate (and the probability of it not activating at all) when in hallways was found to be significantly greater than the time taken for a similar smoke alarm to activate when in the room of fire origin (RFO). The RFO door being closed was also found to be very likely to prevent smoke alarms not in the RFO from activating. Overall, with the RFO door open hallway smoke alarms took some 200-300 s longer to activate than alarms in the RFO. The proportion of alarms that did not activate depended mostly on location but also on detector type. Taking into consideration the likely received sound level and the time and likelihood of alarm activation it is concluded that hallway smoke alarms are much less effective than interconnected smoke alarms in every room. It appears likely that if there were interconnected smoke alarms in every room in a dwelling the probability of an occupant being killed in the event of a fire would be much lower than in the same dwelling with only hallway smoke alarms.
\end{abstract}

KEYWORDS: detection, human factors, smoke alarms.

\section{INTRODUCTION}

Smoke alarms are required to be fitted in dwellings in many jurisdictions. Their purpose is generally stated to be to provide early warning of fire to the occupants. However, as shown below, in many jurisdictions the required smoke alarms are only required to be fitted in hallways (or similar areas), while in others they are required to be fitted in bedrooms and, in stories with no bedrooms, in hallways. In a few jurisdictions the specified smoke alarms are also required to be interconnected so that when one is activated they all sound the alarm signal. Smoke alarms are particularly important for sleeping occupants as they are less likely to become aware of cues to the presence of fire than occupants who are awake. Many studies have shown [14] and it is generally accepted that the louder the sound received by the occupants the more likely it is that they will notice it and react, particularly when they are asleep. It is also generally assumed that the sooner occupants receive a warning after a fire is ignited the more likely it is that they will be able to react appropriately and remain uninjured. Thus smoke alarms should activate as quickly as possible and the sound received by the building occupants should be as loud and effective as a warning as possible. Do hallway smoke alarms that are not interconnected fulfill these requirements?

The optimum alternative to hallway alarms that are not interconnected is obviously interconnected smoke alarms in every room and space where fires start and in every room and space where occupants may be present when fires occur $[5,6]$. Such a smoke alarm system would provide as early detection as possible (limited only by the sensitivity and reliability of the detector mechanisms) and a signal that is as effective as possible at alerting occupants (limited only by the type of signal and loudness of the signal emitted by each alarm). One penalty of this would be the greater number of smoke alarms required for a given 
dwelling and the extra wiring required to interconnect the alarms, both resulting in increased cost. Another penalty may be an increased frequency of false alarms due to the greater number of components and their location in every room. This may require an addition to the smoke alarm system such as an easily accessible wall mounted button to allow building occupants to easily and rapidly cancel the alarm signal for a short duration when they know the signal to be a nuisance alarm and definitely not associated with an unwanted fire. However, for increased fire safety, such difficulties may be warranted and tolerable, but this would also depend on the penalty (in longer activation time and less effective warnings) due to the use of hallway smoke alarms that are not interconnected.

This paper utilizes smoke alarm sound level and activation time measurements obtained in a recent project [5] intended to help determine the most appropriate location(s) of smoke alarms in dwellings undertaken for and partially funded by the Australian Building Codes Board, the organization responsible for the Building Code of Australia (BCA) [7]. The remaining funding was from the Australian Research Council.

The BCA [8] basically only requires smoke alarms in hallways and similar spaces (not interconnected). In contrast the NFPA requirements in the USA have specified interconnected smoke alarms in bedrooms as well as in some hallways for many years $[9,10]$. In the UK the current requirements for normal size dwellings require smoke alarms in circulation areas (basically hallways) of each story and in the principle habitable (e.g. lounge) room [11,12]. In New Zealand the relevant acceptable solution requires smoke alarms to be located in the escape routes (basically hallways) on all levels and in levels containing bedrooms smoke alarms in every bedroom or within $3 \mathrm{~m}$ of every bedroom door [13]. Presumably the latter alarms would be in hallways. The New Zealand regulation states that in the latter case they must be audible to sleeping occupants on the other side of closed doors but fails to specify what this requires in terms of a sound level at the pillow [13]. In the provinces of Ontario and British Columbia in Canada a smoke alarm is required to be installed between each sleeping area and the remainder of the dwelling unit (basically hallways) and at least one smoke alarm is required in each story that does not contain a bedroom $[14,15]$. In Europe smoke alarms are required to be installed so that they can be heard when people are asleep [16]. This document suggests that in dwellings a minimum is interconnected alarms in hallways on every level but also suggests for maximum protection interconnected alarms in every room.

The Australian Standard for emergency notification AS 1670.1 [17] and many other standards specify that the sound level of a smoke alarm should be at least $75 \mathrm{dBA}$ at the pillow. In a recent paper the authors reviewed evidence that clearly indicates that the $75 \mathrm{dBA}$ level is inadequate to reliably awaken many 'at risk' people [6].

The prediction of the sound levels throughout a house using physical models is very difficult and software to do this appears to be unavailable. Sound levels vary widely within rooms, between rooms and in different rooms as there are usually many paths of travel between rooms, many room shapes and sizes and many different materials used as ceilings, walls, floors, doors, windows, furnishings, etc. Added to this there is a great variety of possible surfaces and types of fittings such as doorways, windows, heating and cooling ducts, etc all of which may influence the actual sound level at a particular location by providing travel paths and by reflecting or absorbing sounds. Furnishings, carpets or other floor coverings, and other fittings such as curtains and blinds also may have a great influence on sound transmission and the sound level at a particular location. In some rooms there are appliances or other equipment that emit sounds either constantly or periodically that influence the ambient sound level in these rooms and elsewhere.

In order to change the current Australian requirements there would need to be a substantial expected benefit from the proposed change, that is, a significant reduction in fire fatalities. Assuming that the people and circumstances of potential fire fatalities in the future will be similar to those in the recent past, this means that people similar to those who were recently killed in fires in dwellings would not be killed in similar fires in the future. Thus it is important to understand the people who died recently and the circumstances in which they died. For this reason detailed coronial records relating to 140 accidental residential fatalities were studied [5]. It would be better to have details of more fatalities but these were (and remain) all that are available. (The database is being progressively expanded and the analysis will be repeated when this is complete.) However a number of characteristics of the fatally injured people and the circumstances in which they died are quite clear from the current database and appear unlikely to change substantially in the expanded database. Briefly, of 128 accidental residential building fire fatalities for which there was sufficient information in the database: 
- 18 fatalities ( $13 \%$ of the 128 fatalities) occurred in eight multiple fatality fires:

0 three of the eight fires resulted in the death only of children

0 nine (50\% of the 18 fatalities) were children, the oldest aged 11 years

0 three of the eight fires had no one else (other than those who died) in the dwelling at the time of the fire, in some the only occupants were children

o alcohol was recorded in the bloodstream of five of the nine deceased adults (56\% of the nine adults) in three of the fires but no deceased adult was found to have drugs (prescription and/or illicit) in their blood

o one or more smoke alarms were present in three fires ( $43 \%$ of the seven fires where their presence was known) and they operated in at least one of these fires

o locked doors impeded escape in two of the eight fires, fire growth was too rapid to allow escape and/or the fire was between the occupants and the exit in two of the fires, one of the fatalities was a baby and therefore unable to move, and mobility problems may have impeded the escape of two adults and several other of the younger children

- 74 fatalities (59 \% of the 128 fatalities) occurred in single fatality fires and the person who died was alone in the dwelling at the time of the fire:

o none were children

o 59 were tested for blood alcohol content (BAC) and/or drugs (prescription and/or illicit) and of these 45 ( $76 \%$ of the 59 ) had a BAC $\geq 0.07$ and/or drugs

0 in 39 of these cases where the presence and/or activation of smoke alarms is known:

- $12(31 \%$ of the 39$)$ had none present

- nine (23\% of the 39$)$ had smoke alarms in the room of fire origin (RFO) and, of the nine, five are known to have operated

- 18 (46\% of the 39 ) had smoke alarms but not in the RFO and, of the 18 , eight are known to have operated

o thus (based on the 39 cases with known activation and/or presence):

- in about $31 \%$ of these fatal fires there were no smoke alarms present

- in about $33 \%$ of these fatal fires there were working smoke alarms

- about $36 \%$ of these fatal fires had smoke alarms but they did not operate or their operation is unknown

0 many of the fatally injured occupants responded to the fire cues and/or the smoke alarm sound (if one was present and operated) - 46 ( $74 \%$ of the 62 fires where response is known) responded to the fire and were 'active' in some way during the fire

0 in 33 fires ( $45 \%$ of the 74 fires) there was some physical occurrence that provided some impediment to the ability of the occupant to remain alive:

- in the majority of these their clothing was burning

- in some cases the development of the fire was too rapid or the fire was between the casualty and the exit

- in a few cases locked doors impeded their escape

- 36 ( $28 \%$ of the 128 fatalities) occurred in single fatality fires but the person who died was not alone in the dwelling at the time of the fire:

0 eight were a child (maximum age 12 years)

o 24 of the fatally injured adults were tested for BAC and/or drugs with $10(42 \%$ of the 24 tested) found to have a $\mathrm{BAC} \geq 0.11$ and/or drugs

0 in 22 of these fires the presence and/or activation of smoke alarms is known:

- six ( $27 \%$ of the 22 known) had no smoke alarm present in the dwelling

- four (18\% of the 22 known) had smoke alarms in the RFO and of these two operated

- 12 (55\% of the 22 known) had smoke alarms but not in the RFO and of these six operated

0 thus (based on the 22 cases with known activation and/or presence):

- in about $27 \%$ of these fatal fires there were no smoke alarms present

- in about $36 \%$ of these fatal fires there were working smoke alarms 
- about $37 \%$ of these fatal fires had smoke alarms but they did not operate or their operation is unknown

o 24 people ( $89 \%$ of the 27 fires where response is known) responded to the fire and were 'active' in some way during the fire

0 in 10 of the 36 fires there was some physical impediment to the ability of the fatally injured occupant to remain alive:

- in two their clothing was burning

- in another the development of the fire was too rapid

- in another the fire was between the casualties and the exit

- in some cases locked doors impeded escape

Thus most of the occupants who died in single fatality fires (about $79 \%$ of the 89 known) responded to fire cues and/or the smoke alarm sound (when present). This means that changes in smoke alarm requirements could, at best, produce changes in the timing of their response, not in whether they respond.

It can be seen from this summary that many of the occupants had characteristics that were likely to have severely affected their ability to respond to low level alarm sounds (we consider them to be particularly ' $a$ t risk'), and indeed many of them would be expected to require very loud alarm signals to be likely to respond when asleep [18-26].

Further examination of the 140 fatalities in the database revealed that the great majority of fatalities occurred due to fires that occurred in just three room types:

- a total of 51 fatalities (40\% of known) occurred in fires where the RFO was a bedroom

- for 46 fatalities (36\% of known) the RFO was a lounge room

- for 16 fatalities (12\% of known) the RFO was a kitchen

This totals $88 \%$ of the 129 fatalities with known ignition location. Of the known remainder, five fatalities occurred due to fires that started in ceilings, four on a veranda, three in a laundry and one each in a hallway and a toilet/bathroom.

The same three room types were the location of the great majority of the fatally injured people at the time of ignition although they were not necessarily in the room in which ignition occurred:

- 60 of the fatally injured people (53\% of known) were in bedrooms at the time of ignition

- 34 (30\% of known) were in lounge rooms

- 12 (11\% of known) were in kitchens

These three rooms account for a total of $94 \%$ of 113 fatalities with known location when ignition occurred.

The project consisted primarily of two experimental phases which are covered separately below. The first phase was recording of the time of detection of smoke by smoke alarms placed widely throughout houses. The second phase was measurement of the sound level in houses due to smoke alarms in various locations. A third phase of the project (not covered in this paper) consisted of an evaluation of the costs and benefits of increased smoke alarm requirements in the Australian context including the study of recent fatalities as summarized above. The houses were intended to be representative of typical Australian houses. Three of the five houses were single story, the other two were two stories. None had basements. The sound measurements were conducted in all five houses but the smoke alarm activation measurements were conducted in four houses, three single story and one of two stories. Plans of the houses are shown in [5].

\section{METHOD}

\section{Smoke Detection Measurements}

Full scale models of four houses were constructed in the VU Large Scale Fire Testing Facility. Smoke from a variety of burning materials was then produced at various locations and the time of activation of the domestic smoke alarms in each room and hallway was recorded. The test variables included open and closed doors and windows, the type and brand of smoke alarm, and seven sources of smoke (some from smouldering combustion and some from flaming fires) using a variety of fuels. The smoke alarms used were bought from large hardware stores and were among the types and brands most widely available in Australia at present. 
The full scale model houses were constructed of cardboard with the doors and windows cut out and opened and shut as required for each case tested. Except for the thickness of the walls the model houses accurately reflected the geometry of the actual houses. The smoke sources tested included burning ethanol, braided wick (designated BW below), heptane (H), decalin (D), smouldering wood (RSW), wood crib (WC), smouldering towel (ST) and polyurethane foam (F). These materials and the form of combustion were based on those specified in ISO/TS 7240-9 (2006) "Test fires for fire detectors" [27] for the testing of smoke detectors. It was found in preliminary tests that none of the smoke alarms were activated (even in the RFO) by the burning ethanol, and consequently this fuel was not used in subsequent testing. Minor adjustments were made to the smoke sources due to difficulty in matching exactly the materials and other details specified in Ref. [20]. The following is a brief description of the smoke source fires:

- BW: 90 strands of braided wick (cotton) $800 \mathrm{~mm}$ long which smouldered producing voluminous whitish smoke

- $\mathrm{H}$ : burning $\mathrm{n}$-heptane (plain heptane rather than the heptane (96\%) plus toluene (4\%) specified in Ref. [27]) rapidly produced very black smoke

- D: burning decalin very rapidly produced a great quantity of very black smoke

- WC: the wood crib fire used a small crib of seven layers of sticks (pinus radiata instead of the beechwood specified in Ref. [27]) and burned as a flaming fire with light grey to white smoke

- RSW: the rapidly smouldering wood consisted of 10 dried sticks (again pinus radiata rather than the beechwood specified in Ref. [27]) placed on a hotplate with the temperature of the hotplate raised to $600{ }^{\circ} \mathrm{C}$ over $11 \mathrm{~min}$ as specified in Ref. [27]) produced a greater quantity of light grey smoke

- ST: cotton towel smouldering due to an electric heating element, the light grey smoke produced built up quite slowly

- F: three sheets (each about $500 \mathrm{~mm} \times 500 \mathrm{~mm} \times 20 \mathrm{~mm}$ ) of soft polyurethane foam without flame-retardant additives of density about $20 \mathrm{~kg} / \mathrm{m}^{3}$ were ignited as specified [27] producing much black sooty smoke

Analysis of preliminary experimental results showed that the activation time (if activation occurred: in many tests some alarms did not activate) was very strongly influenced by whether interconnecting doors were open or shut. However, under the very still environmental conditions in the VU Large Scale Fire Testing Facility for these tests it was little influenced by whether windows were open or closed. Consequently all of the results reported here were for tests with the windows closed.

Despite the fact that there was a small gap at the top, bottom and on one side of each (cardboard) door, initial testing indicated that even when the room of fire origin was full of dense smoke, virtually no smoke passed through the closed door into the adjacent room or hallway. This resulted in extremely slow detection of smoke by alarms not in the RFO. On this basis it was decided not to continue with tests with the RFO door closed.

The movement of smoke through a closed door was checked using a real door in a laboratory building (it was still not considered acceptable to severely smoke log rooms in occupied houses) and the situation described above for the model building was found to be reproduced in these situations: with the door closed, unless there was some pressure difference induced between the two rooms by mechanical ventilation or external wind, there was very little smoke movement from one room to another. Thus it was concluded that the movement of smoke through closed doors from low energy smoke sources is minimal and that the time for detection in adjacent rooms is likely to be unacceptably prolonged. Consequently all of the results reported here are for the case with all room doors open.

In each of the model houses smoke was produced using each of the fuels in each room (the RFO) and the time to activation of the smoke alarms fitted in each room and hallway was recorded. The smoke alarms were fitted on the ceiling at the centre of the room with approximately equal distance from the doorway to each alarm. Each room was fitted with two ionization alarms (I), two photoelectric alarms (P) and one dual (ionization and photoelectric) alarm (D). In hallways the dual alarm was omitted. As mentioned previously, the alarms were from two manufacturers numbered 1 and 2 and they are identified as I1, I2, D2, P1 and P2 in this paper. The response of alarms of each type and manufacturer were initially compared using several smoke sources and were found to be very consistent in their activation times. The smoke alarms were cleaned regularly and through repeat testing it was established that there was no trend towards greater nonactivation or longer activation times during the experiments. 


\section{Sound Level Measurements}

The level of sound (in dBA) resulting from smoke alarm sounds emitted in each room in turn was measured with various combinations of room doors open and closed in five currently occupied houses (although the occupants were not present during the testing). The doors were either completely open or completely closed. Two sounds at two set levels were emitted from positions close to the middle of the ceiling in each room and hallway referred to below as the room of sound origin (RSO). The recorded sounds were emitted from a large downward facing speaker at 85 and $105 \mathrm{dBA}$ sound levels when measured $1.0 \mathrm{~m}$ directly below the speaker.

The sounds used were the $\sim 3100 \mathrm{~Hz}$ sound currently used in Australia in domestic smoke alarms and the $520 \mathrm{~Hz}$ square wave sound used in the testing of the ability of these and other sounds to arouse various groups of sleeping people from deep sleep [1-4, 18-26]. The $\sim 3100 \mathrm{~Hz}$ sound is a quite pure tone while the $520 \mathrm{~Hz}$ square wave sound is a complex sound with intensity peaks at the fundamental frequency $(520 \mathrm{~Hz})$ and at the odd numbered harmonics of this frequency. Both are specified and discussed in detail in Refs. $[14,18]$. The differences between the sounds are likely (for the same emitted sound level at the speaker) to result in different sound levels at positions further from the speaker and in differences in the sound level perceived by the human ear despite them being at the same measured sound level (dBA).

The sound levels in the rooms were measured in positions diagonally opposite the room door at approximately pillow height to simulate the likely sound level that sleeping people would experience. All of the measurements were conducted in daytime with the house unoccupied using recently calibrated Lutron SI-4001 sound meters with the settings on "slow response" and "maximum hold". In most houses the ambient sound level in most rooms was generally in the range 35-40 dBA with occasional higher excursions when, for example, an aircraft passed overhead or a truck passed by. In some rooms the ambient sound level was slightly higher.

\section{EXPERIMENTAL RESULTS}

\section{Smoke Detection Measurements}

The activation times recorded for each type of alarm, manufacturer and location in this project may be compared against those of another type, manufacturer or location but should not be treated as indicating the likely response time in any particular real fire situation or in any other dwelling. The measured smoke alarm activation times are tabulated in Ref. [5].

In many tests some of the smoke alarms did not activate. This should not be taken to indicate that they were faulty. Indeed, no alarms were found to consistently fail to operate. In the RFOs one brand of the ionization alarms and the dual alarms operated in all tests (100\% in 174 tests for ionization, $100 \%$ in 163 tests for dual), while the other ionization alarm operated in all but one of 174 tests. In comparison the photoelectric alarms were not as successful with $89 \%$ operating for one brand and $91 \%$ operating for the other in 174 tests. However, the location of the alarms was of more significance than the brand or type of alarm. In the hallway in the single story houses the proportion that operated was $95 \%$ and $98 \%$ for the two brands of ionization alarms in 128 tests compared with $84 \%$ and $77 \%$ for the photoelectric alarms. One of the single story houses had a second hallway with slightly different results - the ionization alarms operated in $84 \%$ and $91 \%$ of 44 tests and both brands of photoelectric alarms operated in $82 \%$ of these tests. There were 46 tests in the two story house. In the second story of the two story house $74 \%$ and $80 \%$ of ionization alarms and $61 \%$ and $48 \%$ of the photoelectric alarms operated. In the bottom story of this house both brands of ionization alarms operated in only $50 \%$ of tests while for the photoelectric alarms the comparable percentages were $57 \%$ and $48 \%$.

It is clear from these figures that with the RFO door open, and whatever type of alarm is used, there is a significant drop in the percentage of alarms that operate for hallway alarms compared with in-room (RFO) alarms. As might be expected the reduction in operating hallway alarms was greater in the two story house compared with the single story houses, and was much greater in the lower story when the RFOs were in the upper story. Overall the percentage of tests in which photoelectric alarms did not operate was greater than for the ionization alarms. 
In the following table and figures it should be remembered that only the alarms that operated are included. The alarms that did not operate either would never have operated in these tests, or would have taken considerably longer to operate than the slowest operating alarm, as monitoring for alarm operation was continued for substantial periods after the last alarm operated.

Table 1 shows the median, mean, maximum and minimum time of operation of smoke alarms that operated in the RFO and in hallways to allow comparisons between the times of operation in these locations. Histograms of the time of operation of the various types of smoke alarms in these locations are shown in Fig. 1. The figures in Table 1 show that both the median and mean times of operation were lower in these tests for the ionization alarms than for the photoelectric alarms. There were however much greater differences between the medians and means for each type of alarm between those in the RFO and those in either of the hallways. The hallway medians and means are very significantly greater than those for the RFOs. There are also significant differences between the means and the medians which reflect the skewed distributions that are apparent in Fig. 1. The spread of the times of operation are also much greater for the hallway alarms than the RFO alarms.

It is difficult to obtain an appreciation of the actual difference between the times of operation of the hallway alarms and the RFO alarms from the histograms in Fig. 1. For this reason, and in order to obtain a better appreciation of differences between the times of operation in the RFO and the hallways, Fig. 2 shows these differences in two different ways. The first measure shown is the ratio of the time of operation in hallways to the time of operation of the same type of alarm in the RFO. The second measure shown in Fig. 2 is the difference between the time of operation of the hallway alarms and the time of operation of the same type of RFO alarms.

It can be seen by examining the histograms in Fig. 2 that for all smoke alarm types almost all of the times of operation in the hallways were over twice the times of operation in the RFO, and in many cases the ratio was much higher. The histograms of the increase in time of smoke alarm operation in the hallways over that in the RFOs when compared with the histograms in Fig. 1 appear to largely parallel those for the hallway alarm activation times. Increases in activation time of $100 \mathrm{~s}$ are very common with the majority of increases being well above this time, and in some cases they are very much above this figure. This is clarified in Tables 2 and 3 which show the median and mean of two quantities, the ratio of hallway smoke alarm activation time to RFO activation time in Table 2 and the differences between the hallway and RFO activation times in Table 3.

Table 1. Time of operation (s) of smoke alarms in the RFO and in hallways.

\begin{tabular}{|c|c|c|c|c|c|c|c|c|c|c|c|c|}
\hline \multirow{2}{*}{ Quantity } & \multicolumn{4}{|c|}{ RFO } & \multicolumn{4}{|c|}{ Hall A } & \multicolumn{4}{|c|}{ Hall B } \\
\hline & I1 & I2 & P1 & $\mathbf{P 2}$ & I1 & $\mathrm{I} 2$ & P1 & $\mathbf{P 2}$ & I1 & I2 & P1 & P2 \\
\hline $\mathrm{n}$ & \multicolumn{4}{|c|}{174} & \multicolumn{4}{|c|}{128} & \multicolumn{4}{|c|}{46} \\
\hline Median & 97 & 76 & 175 & 202 & 285 & 250 & 336 & 338 & 309 & 293 & 361 & 384 \\
\hline Mean & 199 & 179 & 216 & 251 & 426 & 387 & 473 & 510 & 401 & 412 & 562 & 508 \\
\hline Maximum & 1177 & 1064 & 879 & 966 & 1722 & 1761 & 3038 & 4000 & 1494 & 1478 & 2678 & 1472 \\
\hline Minimum & 0 & 0 & 28 & 45 & 37 & 32 & 52 & 81 & 25 & 22 & 104 & 124 \\
\hline
\end{tabular}

Table 2. Ratio of time of operation of smoke alarms in hallways and the RFO.

\begin{tabular}{|l|c|c|c|c|c|c|c|c|}
\hline \multirow{2}{*}{ Quantity } & \multicolumn{4}{|c|}{ Hall A } & \multicolumn{4}{c|}{ Hall B } \\
\cline { 2 - 9 } & I1 & I2 & P1 & P2 & I1 & I2 & P1 & P2 \\
\hline Median & 2.3 & 2.6 & 1.9 & 1.8 & 3.4 & 3.3 & 2.3 & 2.0 \\
\hline Mean & 3.2 & 5.4 & 2.7 & 2.6 & 4.9 & 5.2 & 2.9 & 2.3 \\
\hline
\end{tabular}

Table 3. Difference between time of operation of smoke alarms in hallways and the RFO (s).

\begin{tabular}{|l|c|c|c|c|c|c|c|c|}
\hline \multirow{2}{*}{ Quantity } & \multicolumn{4}{|c|}{ Hall A } & \multicolumn{4}{|c|}{ Hall B } \\
\cline { 2 - 9 } & I1 & I2 & P1 & P2 & I1 & I2 & P1 & P2 \\
\hline Median & 125 & 124 & 117 & 124 & 186 & 153 & 187 & 167 \\
\hline Mean & 226 & 207 & 263 & 270 & 258 & 252 & 339 & 259 \\
\hline
\end{tabular}




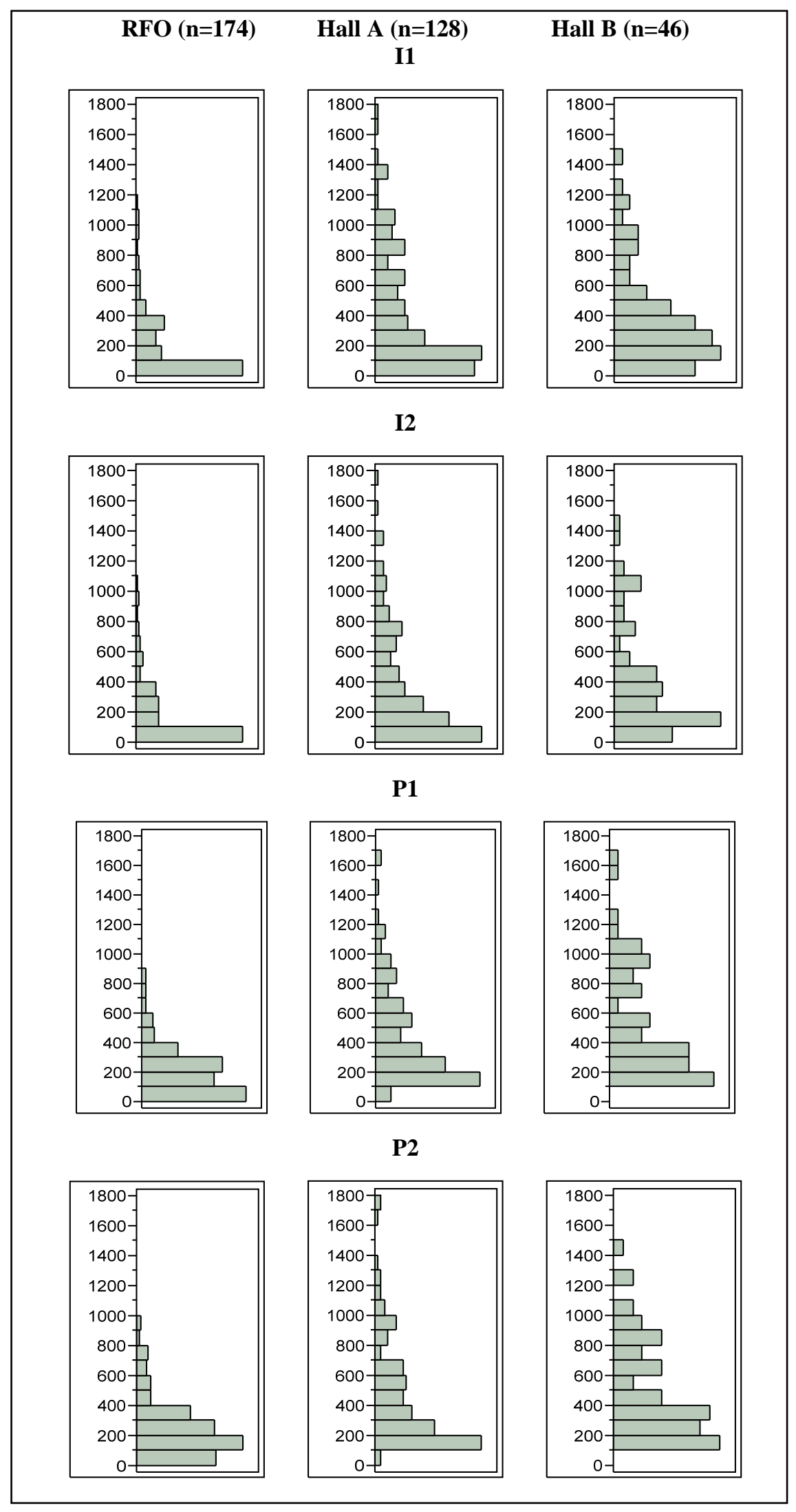

Fig. 1. Histograms of smoke alarm activation times (s) for each detector type and location. 


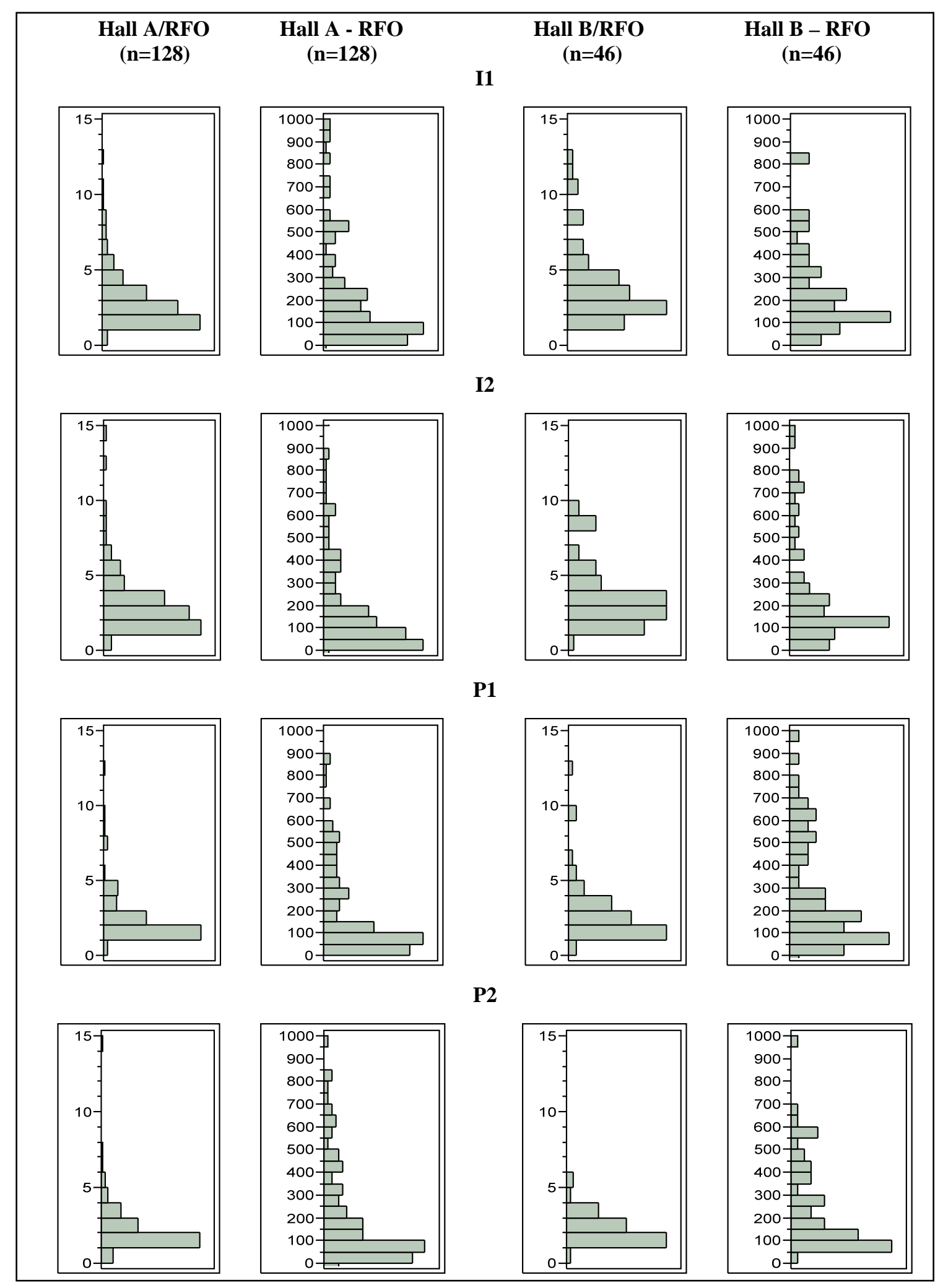

Fig. 2. Histograms of ratio of hallway smoke alarm activation time to RFO activation time and of the difference between hallway activation time and RFO activation time (s). 
Based on the figures in Table 2 it is apparent that the effect of the hallway location rather than the RFO location is greater for the ionization alarms than for the photoelectric alarms but in summary it is reasonable to say (based on the medians) that for approximately $50 \%$ of the ratios the activation time in the hallways is a factor of two higher than for the same alarm in the RFO and the difference in the means is greater. From Table 3 it is apparent that the time difference is about $120 \mathrm{~s}$ for about $50 \%$ of the cases for both alarm types and that mean differences are between 200 and $300 \mathrm{~s}$.

Overall, it is reasonable to conclude that, even when the RFO door is open, there is generally a considerable penalty (delay in notification) for hallway smoke alarms compared with smoke alarms in the RFO whatever type of smoke alarm is used. That is, there is an increase in the time to operation for a specific type of alarm for smoke alarms placed in hallways compared with the same alarm in the RFO. An operation time well over three times that in the RFO is common. This translates to increases in the time of operation of $200 \mathrm{~s}$ or more in a large proportion of these tests. These increases could, in turn, translate to considerable delays in the time of awareness of the occupants in the RFO or elsewhere and therefore result in considerable penalties for them in terms of increased fire growth and increased smoke density in the exit paths. This would result in a considerably increased likelihood that they would not escape uninjured, if at all.

The preceding results are for the case with the RFO door open. With the RFO door closed the difference in operation times between alarms in the RFO and those in hallways (if the hallway alarms operated at all before the fire became serious enough to impinge on or even burn through the RFO door) would be considerably greater. This would make the situation even more dangerous for occupants in the RFO and possibly for other occupants also.

\section{Sound Level Measurements}

The sound level results for the sound level in rooms due to hallway smoke alarms in the five houses in which tests were conducted are summarized numerically in Table 4 and presented as histograms in Fig. 3. The complete set of sound level data is tabulated in Ref. [5].

In Table 4 and in Fig. 3 the sound level data for sounds emitted in hallways is classified in terms of the open or closed state of the room door, and in terms of the sound type and level. Most rooms are divided from other rooms and hallways by walls (some including doors) but others are essentially the same space with no wall or only a partial wall or bench separating them. Hallways are considered not to have doors, but the rooms connected to them usually do have doors.

Table 4. Summary of sound level in rooms resulting from sounds emitted in hallways.

\begin{tabular}{|c|c|c|c|r|r|r|r|}
\hline \multirow{3}{*}{ Doors } & $\begin{array}{c}\text { Signal } \\
\text { type/level } \\
\text { (Hz/dBA) }\end{array}$ & $\mathbf{n}$ & $\begin{array}{c}\text { Maximum } \\
\text { reading } \\
\text { (dBA) }\end{array}$ & $\begin{array}{c}\text { Median } \\
\text { reading } \\
\text { (dBA) }\end{array}$ & $\begin{array}{c}\text { Minimum } \\
\text { reading } \\
\text { (dBA) }\end{array}$ & $\begin{array}{c}\text { Mean } \\
\text { (dBA) }\end{array}$ & $\begin{array}{c}\text { \% }< \\
\mathbf{7 5} \mathbf{~ d B A}\end{array}$ \\
\hline \multirow{4}{*}{ Closed } & $\mathbf{3 1 0 0 / 8 5}$ & 42 & 55.9 & 44.8 & 37.4 & 45.5 & 100 \\
\cline { 2 - 8 } & $\mathbf{3 1 0 0 / 1 0 5}$ & 42 & 76.8 & 62.3 & 49.3 & 62.9 & $\sim 95$ \\
\cline { 2 - 8 } & $\mathbf{5 2 0 / 8 5}$ & 42 & 67.5 & 52.7 & 39.2 & 51.8 & 100 \\
\cline { 2 - 8 } & $\mathbf{5 2 0 / 1 0 5}$ & 42 & 86.9 & 72.4 & 55.7 & 71.1 & $\sim 70$ \\
\hline \multirow{4}{*}{ Open } & $\mathbf{3 1 0 0 / 8 5}$ & 72 & 74.8 & 57.2 & 40.0 & 56.9 & 100 \\
\cline { 2 - 8 } & $\mathbf{3 1 0 0 / 1 0 5}$ & 72 & 94.6 & 75.7 & 59.8 & 75.8 & $\sim 45$ \\
\cline { 2 - 8 } & $\mathbf{5 2 0 / 8 5}$ & 72 & 76.8 & 64.2 & 46.4 & 63.2 & $\sim 95$ \\
\cline { 2 - 8 } & $\mathbf{5 2 0 / 1 0 5}$ & 72 & 104 & 84.0 & 64.4 & 83.7 & $\sim 20$ \\
\hline
\end{tabular}

In Table 4 for two cases (room doors closed and open) and for each combination of sound type ( $\sim 3100 \mathrm{~Hz}$ current smoke alarm sound and $520 \mathrm{~Hz}$ square wave) and sound level emitted in the hallway (85 or $105 \mathrm{dBA}$ ) the number of readings ( $\mathrm{n}$ ), the maximum, median, minimum and mean sound levels are tabulated along with the percentage of readings in which the sound level was less than the $75 \mathrm{dBA}$ reference sound level mentioned above. It would be preferable that the sound level be well above the 
$75 \mathrm{dBA}$ reference level in $100 \%$ of cases to ensure the great majority of rooms had a sound level reasonably likely to be effective in warning sleeping people.

Examination of Table 4, firstly for the base case of the current $\sim 3100 \mathrm{~Hz}$ smoke alarm sound emitted in hallways at $85 \mathrm{dBA}$, reveals that the measured values for the room doors closed case varied from a maximum of about $56 \mathrm{dBA}$ to a minimum of about $37 \mathrm{dBA}$ (which would be at or very close to the ambient sound level without the smoke alarm sounding). The median value (the value in the middle of all of the readings when ordered from maximum to minimum) was about $45 \mathrm{dBA}$. Thus all (100\%) of the measured values were well below the $75 \mathrm{dBA}$ reference level. This was also the case even with the room doors open. The maximum measured sound level with the doors open was just below the reference level at $74.8 \mathrm{dBA}$ but the great majority of readings were well below this level.

Even when the emitted $\sim 3100 \mathrm{~Hz}$ sound level was raised to $105 \mathrm{dBA}$ the sound level measured in every room was below the $75 \mathrm{dBA}$ level for the doors closed case and for the doors open case was below this level for about $45 \%$ of the rooms.

For the $520 \mathrm{~Hz}$ square wave sound the measured sound levels in the rooms were somewhat higher but at the $85 \mathrm{dBA}$ emitted sound level with the room doors closed $100 \%$ of measured values remained below the $75 \mathrm{dBA}$ reference sound level. With the room doors open the reference level was only exceeded by about $5 \%$ of measured values. Even with this sound at the higher emitted sound level of $105 \mathrm{dBA}$ about $70 \%$ of the measured values were below $75 \mathrm{dBA}$ with the doors closed and about $20 \%$ with the doors open. Thus it is clear that even smoke alarms emitting these sounds at the levels tested would not provide satisfactory warning to the occupants of the dwelling unless they happen to be in the same hallway as the smoke alarm.

However, neither of these increases would be as effective as simply placing an $85 \mathrm{dBA}$ sound emitter (that is, an interconnected smoke alarm) in every room.

The histograms in Fig. 3 show that the distributions of the measured sound levels varied considerably in shape in addition to the variations in levels discussed above.

\section{DISCUSSION}

In the USA and several other countries smoke alarms are specified in bedrooms instead of or as well as in hallways. How would this compare with smoke alarms in all rooms assuming the Australian casualty data discussed above applies? The room of fire origin was a bedroom for $40 \%$ of the fatalities, so for $60 \%$ it was another room or space. The fatally injured person was located in a bedroom at the time of ignition for $53 \%$ of fatalities, so for $47 \%$ the person was located elsewhere. So this means that for about $60 \%$ of fatalities the fire was not in a bedroom (resulting in a substantial delay in detection) and for about $50 \%$ the person was not located in a bedroom (resulting in a level of alarm sound very likely not adequate to assure that the person becomes aware of the fire). If the $75 \mathrm{dBA}$ sound level at the pillow required by some standards for smoke alarms is important in fire emergencies, it appears reasonable to conclude that about $50 \%$ of at risk occupants, perhaps more, would not be adequately served by interconnected smoke alarms in bedrooms and hallways compared with interconnected smoke alarms in all rooms which would be expected to better assist $100 \%$ of at risk occupants.

\section{CONCLUSIONS}

Taking into account the circumstances of the fatal fires summarized above and the characteristics of many of the fatally injured people (many being at risk) it is apparent that a sound level of $75 \mathrm{dBA}$ (but perhaps higher) is preferable in rooms they might occupy when a fire occurs. This would make it more likely (but not certain) that building occupants similar to those recently killed in dwelling fires in Australia would respond when asleep.

The sound level in rooms due to hallway alarms was found to vary considerably but for the current smoke alarm sound at the current minimum emitted sound level $(\sim 3100 \mathrm{~Hz}$ sound at $85 \mathrm{dBA})$ it was found to generally be considerably below the $75 \mathrm{dBA}$ level with the room doors open and was even lower with the doors closed.

The time taken for a particular type of smoke alarm to activate when in a hallway (and the probability of it not activating at all) was found to be significantly greater than the time taken for a similar smoke alarm to 
activate when in the RFO, even with the RFO door open. The RFO door being closed was also found to be very likely to prevent smoke alarms in hallways from activating, and at the very least to very substantially delay activation. Overall, hallway smoke alarms were found to take substantially longer and to be significantly less likely to activate than similar alarms in the RFO.

It is concluded that when the received sound level, and the time and likelihood of activation are considered, hallway smoke alarms are considerably less effective than interconnected smoke alarms in every room. In comparison, interconnected smoke alarms in every room provide quicker activation and as loud and effective a warning as possible with the equipment used.

However, in about $90 \%$ of fatal fires either the fire start or the fatally injured person, was located in one of three types of room: bedroom, lounge room or kitchen. Thus about $90 \%$ of any benefit to be gained by requiring smoke alarms in every room can be gained by requiring interconnected smoke alarms in these rooms. (However due to the possibility of excessive false alarms if smoke alarms are fitted in kitchens it may be preferable to instead to require suitable interconnected heat detector based alarms in kitchens.)

\section{Room doors open}

Room doors closed

Sound $=3100 \mathrm{~Hz}$, RSO level $=85 \mathrm{dBA}$
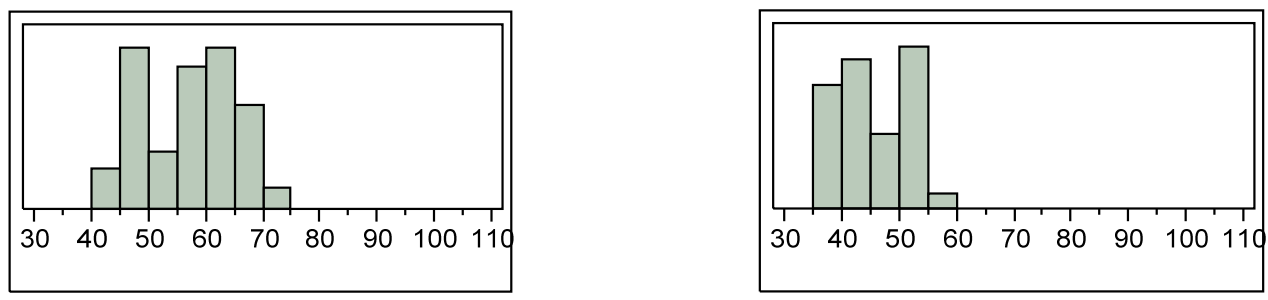

Sound $=3100 \mathrm{~Hz}$, RSO level $=105$
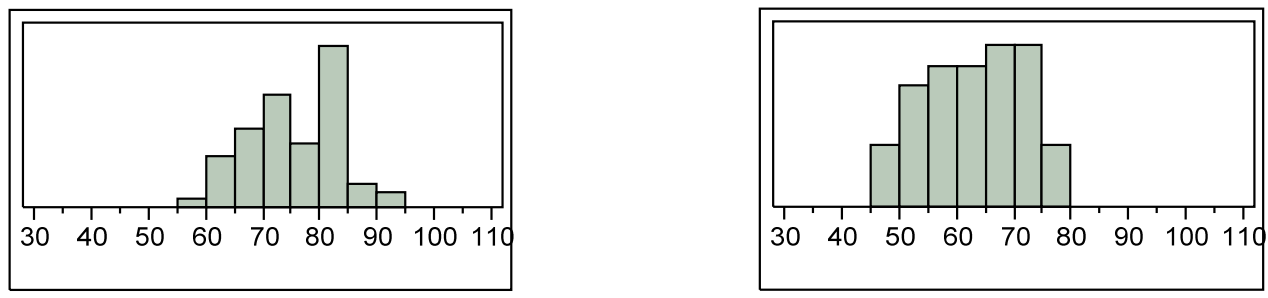

Sound $=520 \mathrm{~Hz}$, RSO level=85
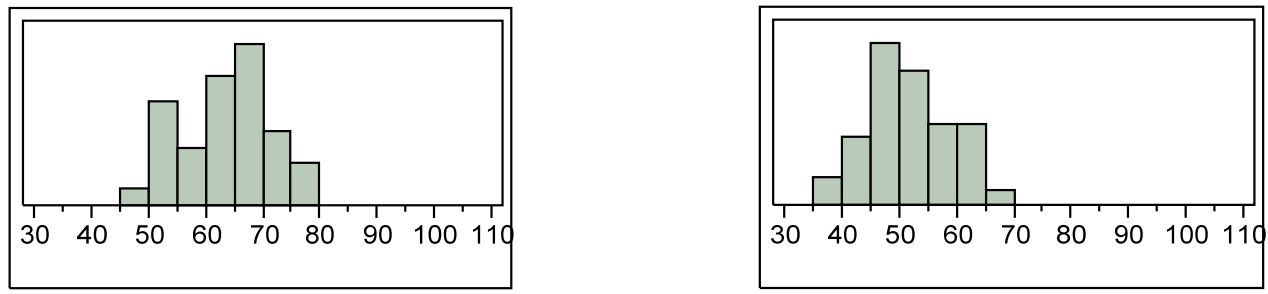

Sound $=520$ Hz, RSO level $=105$
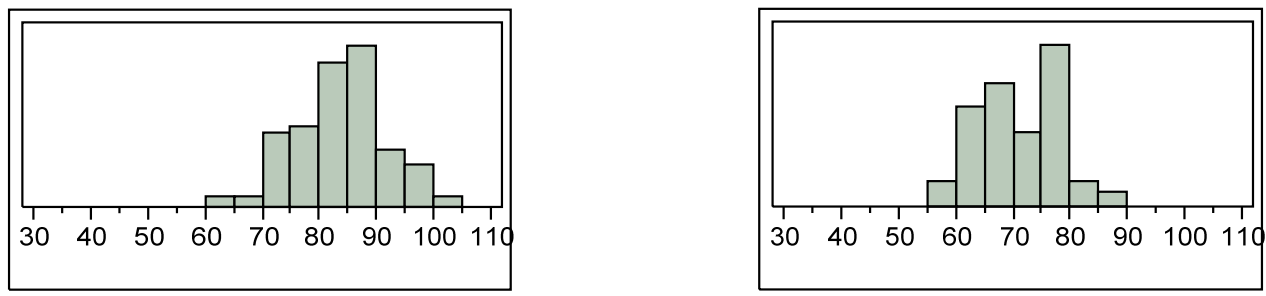

Fig. 3. Histograms of sound levels (dBA) in rooms resulting from sounds emitted in hallways. 


\section{REFERENCES}

[1] Bruck, D., and Thomas, I., (2008) Comparison of the effectiveness of different emergency notification signals in sleeping older adults. Fire Technology 44:15-38, http://dx.doi.org/10.1007/s10694-007-0017-5

[2] Bruck, D., Reid, S., Kouzma, J., and Ball, M., (2004) The effectiveness of different alarms in waking sleeping children. Proceedings of the Third Human Behaviour in Fire Conference (Belfast). Interscience Communications, London, pp 279-290.

[3] Ball, M., and Bruck, D., (2004) The salience of fire alarm signals for sleeping individuals. Proceedings of the Third Human Behaviour in Fire Conference (Belfast). Interscience Communications, London, pp 303-314.

[4] Ball, M., and Bruck, D., (2004) The effect of alcohol upon response to different fire alarm signals. Proceedings of the Third Human Behaviour in Fire Conference (Belfast). Interscience Communications, London, pp 291-302.

[5] Thomas, I. and Bruck, D., (2010) Smoke Alarms in Dwellings: Timely Activation and Effective Notification, Centre for Environmental Safety and Risk Engineering, Victoria University, Melbourne Australia.

[6] Thomas, I. and Bruck, D., (2010) Smoke Alarm Sound Levels in Australian Houses, $8^{\text {th }}$ AsiaOceania Symposium on Fire Science and Technology, Melbourne, Australia, December 2010.

[7] Australian Building Codes Board (2008) Building Code of Australia Volumes 1 and 2, Australian Building Codes Board, Canberra.

[8] Australian Building Codes Board (2008) Building Code of Australia Volume 2, Class 1 and Class 10 Buildings, Australian Building Codes Board, Canberra.

[9] Lee, A., (2005) The Audibility of Smoke Alarms in Residential Homes, CPSC-ES-0503, US Consumer Product Safety Commission, Bethesda, MD.

[10] NFPA 72 (2002), National Fire Alarm Code, National Fire Protection Association, Quincy, MA.

[11] North Down Borough Council Building Control (2010) Smoke and Heat Detectors in Dwellings, http://www.northdown.gov.uk/uploads/docs/NDBC_BC_Smoke, Heat_Detectors.pdf.

[12] British Standards Institute (2004) BS 5839-6:2004, Fire detection and fire alarm systems for buildings. Code of practice for the design, installation and maintenance of fire detection and fire alarm systems in dwellings, BSI, London, September 2004.

[13] Department of Building and Housing (2008) NZ Compliance Document for New Zealand Building Code Clause F7 Warning Systems - Third Edition, Department of Building and Housing, Wellington NZ.

[14] Ontario Government (2007) Fire Protection and Prevention Act, 1997 - O. Reg. 213/07. Queen's Printer for Ontario, Canada.

[15] Ministry of Public Safety and Solicitor General, British Columbia (2010) BC Fire Code Requirements for Smoke Alarms, Ministry of Public Safety and Solicitor General, British Columbia, Canada.

[16] Confederation of Fire Protection Associations Europe (2008) CFPA-E Guideline No 10: Smoke alarms in the home, Confederation of Fire Protection Associations Europe.

[17] Standards Australia (2004) Australian Standard (AS) 1670.1 Fire detection, warning, control and intercom systems - System design, installation and commissioning. Part 1: Fire. Standards Australia, Sydney Australia.

[18] Bruck D., and Thomas I.R., (2009) Community based research on the effectiveness of the home smoke alarm in waking up children. Shields J (ed.) Proceedings of the Fourth Human Behaviour in Fire Conference. (Cambridge) Interscience Communications, London, pp 335-344. 
[19] Bruck, D., Thomas, I., (2009) Smoke alarms for sleeping adults who are hard-of-hearing: comparison of auditory, visual and tactile signals. Ear \& Hearing, 30:73-80, http://dx.doi.org/10.1097/AUD.0b013e3181906f89

[20] Bruck, D., Ball, M., Thomas, I., and Rouillard, V., (2009) How does the pitch and pattern of a signal affect auditory arousal thresholds? J Sleep Res, 18:196-203, http://dx.doi.org/10.1111/j.1365-2869.2008.00710.x

[21] Bruck, D., Thomas, I., Ball, M., (2007) Waking effectiveness of alarms (auditory, visual and tactile) for the alcohol impaired. The Fire Protection Research Foundation, Quincy, USA.

[22] Bruck, D., and Brennan, P., (2001) Recognition of fire cues during sleep. Shields J (ed.) Proceedings of the Second International Symposium on Human Behaviour in Fire. Interscience Communications, London, pp. 241-252.

[23] Bruck, D., and Thomas, I., (2009) Strobe lights versus auditory smoke alarm signals: Effectiveness for waking up selected populations. Ir J Psychology, 30:21-36.

[24] Bruck, D. and Thomas, I.R., 2009. Towards a Better Smoke Alarm Signal - An Evidence Based Approach. Fire Safety Science 9: 403-414. http://dx.doi.org/ 10.3801/IAFSS.FSS.9-403

[25] Bruck, D., and Thomas. I., (2007) Waking effectiveness of alarms (auditory, visual and tactile) for adults who are hard of hearing. The Fire Protection Research Foundation, Quincy, USA.

[26] Cruickshanks, K.J., Wiley, T.L., Tweed, T.S., Klein, B.E.K., Klein, R., Mares-Perlman, J.A. and Nondahl D.M., (1998) Prevalence of hearing loss in older adults in Beaver Dam, Wisconsin: the epidemiology of hearing loss study. Am J Epidemiol, 148(9): 878-886.

[27] International Organization for Standardization (2006) ISO/TS 7240-9 Fire detection and alarm systems Part 9: Test fires for fire detectors, International Organization for Standardization, Geneva, Switzerland. 